\title{
Cytokine and Angiogenic Factor Profile
}

National Cancer Institute

\section{Source}

National Cancer Institute. Cytokine and Angiogenic Factor Profile. NCI Thesaurus. Code C123804.

A data set that both identifies and quantifies the levels of expression for all the cytokines and angiogenic factors present in a biological sample or specimen. 